\title{
Recent advances in small molecular, non-polymeric organic hole transporting materials for solid-state DSSC
}

\author{
Thanh-Tuan Bui ${ }^{\mathrm{a}}$ and Fabrice Goubard ${ }^{\mathrm{b}}$ \\ Laboratoire de Physicochimie des Polymères et des Interfaces, Université de Cergy-Pontoise, 5 mail Gay Lussac, \\ Neuville-sur-Oise, 95031 Cergy-Pontoise Cedex, France
}

Received: 31 December 2012 / Received in final form: 17 June 2013 / Accepted: 28 June 2013

Published online: 2 October 2013

(C) Bui and Goubard, published by EDP Sciences, 2013

\begin{abstract}
Issue from thin-film technologies, dye-sensitized solar cells have become one of the most promising technologies in the field of renewable energies. Their success is not only due to their low weight, the possibility of making large flexible surfaces, but also to their photovoltaic efficiency which are found to be more and more significant ( $>12 \%$ with a liquid electrolyte, $>7 \%$ with a solid organic hole conductor). This short review highlights recent advances in the characteristics and use of low-molecular-weight glassforming organic materials as hole transporters in all solid-state dye-sensitized solar cells. These materials must feature specific physical and chemical properties that will ensure both the operation of a photovoltaic cell and the easy implementation. This review is an english extended version based on our recent article published in Matériaux \& Techniques 101, 102 (2013).
\end{abstract}

\section{Construction and performance of dye-sensitized solar cell}

The energy-scenario analysis in 2050 plans an increase until $300 \%$ of the world energy consumption. Such a need cannot be exclusively satisfied by the fossil fuels, humanity has to turn to renewable energies and notably towards the potentiality of solar energy. Photovoltaics is a promising renewable energy technology that converts sunlight to electricity, with broad potential to contribute significantly to solving the future energy problem that humanity faces. Historically, in 1954, Bell Labs created the first siliconbased solar cells with $6 \%$ efficiency [1]. To date, inorganic semiconductor solar cells dominate commercial markets, with crystalline Si having an $80 \%$ share; the remaining $20 \%$ is mostly thin film solar technology, such as CdTe and CuInGaSe [2]. However, the use of this conventional silicon involves a non-negligible production cost, in particular because of the silicon purification process to reach the solar-grade silicon. This cost strikingly reduces the competitiveness of these silicon cells compared with the traditional sources of energy for the ground applications.

Since the last two decades, low-cost solutions have emerged mainly using thin-film solar photovoltaic technologies. Among them, a new type of cell, known as dyesensitized solar cells (DSSC) [3], has been studied to develop low-cost photovoltaic devices. In this type of cell,

\footnotetext{
a e-mail: thanh-tuan.bui@u-cergy.fr

b e-mail: fabrice.goubard@u-cergy.fr
}

a light-harvesting material, generally a molecular dye absorbs photons and is photoexcited. The photogenerated electrons and holes from the dye are quickly separated and transferred into two different transporting media (metallic oxide and electrolyte) reducing strongly the electron-hole recombination in the absorber material. Moreover, the device is based on the superposition of active layers whose thicknesses are ten to twenty-folds inferior to that of crystalline silicon wafers. In addition, the requested purity of materials is 10 to 100 times less than for a silicon device.

The DSSC is composed of a photo-anode and a photoinert counter electrode (cathode) sandwiching a redox mediator (Fig. 1). It consists of five materials: (1) a fluorine-doped $\mathrm{SnO}_{2}$ (FTO) coated glass substrate, (2) a nanocrystalline $\mathrm{TiO}_{2}$ semiconductor thin film, (3) a photosensitizer, organic dye or metal coordination complex, (4) an electrolyte containing redox mediator, and (5) a platinum-coated glass substrate (Fig. 1).

A schematic presentation of the operating principles of DSSC is shown in Figure 1 [4]. Upon absorption of photons, dye molecules anchored on the $\mathrm{TiO}_{2}$ surface are excited and an electron passes from the highest occupied molecular orbital (HOMO) to the lowest unoccupied molecular orbital (LUMO). The excited dyes inject electrons from their LUMOs into the conduction band of the oxide. The oxidized dyes are then regenerated by electron donation from the redox mediator, such as the iodide/triiodide couple. The iodide is regenerated, in turn, by the reduction of triiodide at the counter electrode, with 

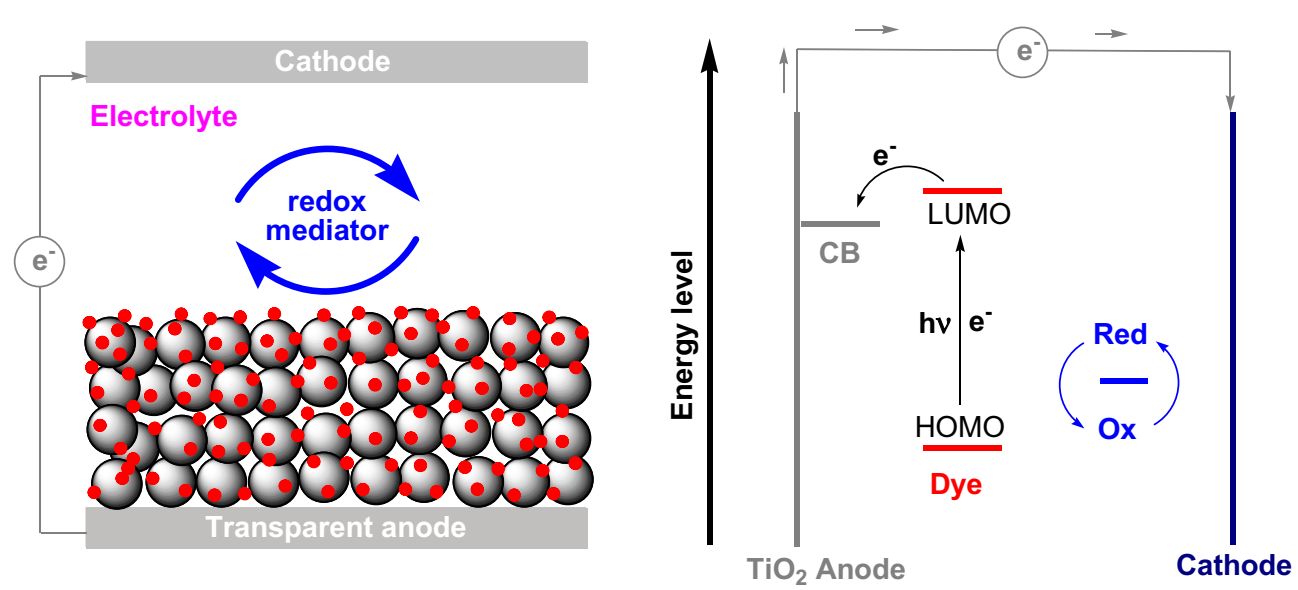

Fig. 1. Schematic presentation of liquid electrolyte-based DSSC and its operation principle.

the circuit being completed via electron migration through the external load.

In 1991, O'Regan and Grätzel [5] published a seminal paper on DSSC based on the mechanism of a fast regenerative photoelectrochemical process. The overall efficiency of this new type of solar cell was 7.1-7.9\% (under simulated solar light) with $\mathrm{I}^{-} / \mathrm{I}_{3}^{-}$as redox mediator and $\mathrm{Ru}$ complex as dye. The originality and the device performances are mainly governed by (i) the high surface area and the controlled nanoporosity of the oxide materials, and (ii) the high efficiency regeneration of the photooxidized dye molecules induced with an iodide/triiodide redox electrolyte.

Since the last two decades, many research groups have been focusing their efforts into developing and optimizing all the processes and materials constituting a DSSC [3,6]. Nowadays, the photoconversion efficiencies reach over $12 \%$ for small single cells $[7,8]$ and about $10 \%$ for modules [9], connected with high stability upon sunlight exposure. One of the manufacturing challenges for DSSCs is the need for a robust sealing process that would prevent the liquid electrolyte in the cells from leakage and evaporation. Moreover, the electrolyte, the iodide/triiodide redox couple, is corrosive to the surroundings. These problems create difficulties for the large scale production and greatly curb the commercialization of DSSC [10-12]. For this reason, "all solid-state" DSSCs have emerged in an attempt to replace the liquid electrolytes with small organic or inorganic hole conductors, $\pi$-conjugated polymers, or gel electrolytes. These molecules, except polymeric materials, by their small size can infiltrate into the pores of metallic oxide to replace the liquid electrolyte. The structure and the operation principle of the device are thus modified (Fig. 2). Here, hole transfer occurs directly from the dye to the hole-transporting materials (HTM), with the holes being transported via hopping between electronic states on the organic molecules to a metallic counter electrode.

To well ensure the operation cycle of a solid-state DSSC, several characteristics are essential for any organic $p$-type semiconductor.

(1) It must be able to be deposited within the porous nanocrystalline layer: an amorphous state is required

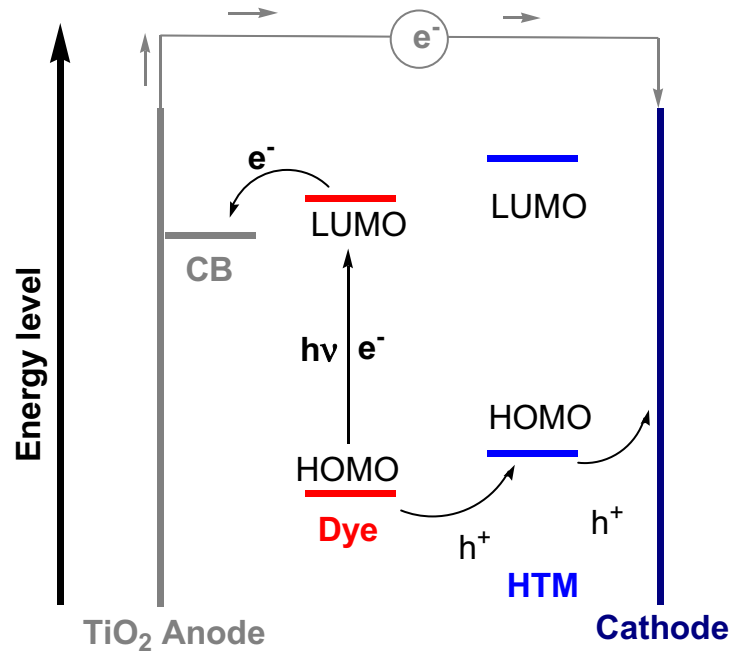

Fig. 2. Operation principle of solid state DSSC device.

with a glass transition superior to room temperature. The amorphous phase, with small molecular size and high solubility, facilitate pore filling, allowing good contact with the dye and hence the best efficiency of the cell.

(2) It must be able to collect holes from the sensitizing dye after the dye has injected electrons into the $\mathrm{TiO}_{2}$; that is why the HOMO energy level of $p$-type semiconductors must be located above the ground state level of the dye.

(3) A method must be available for depositing the $p$-type semiconductors without dissolving or degrading the monolayer of dye on $\mathrm{TiO}_{2}$ nanocrystallites.

(4) It must be transparent in the visible spectrum with no absorption screen effect compared to dye.

(5) The mobility of charge carriers in the organic $p$-type semiconductors must be higher and substantially equal than that in the nanoporous $\mathrm{TiO}_{2}$ layer avoiding a charge excess at the interface between active layer and electrode.

A solid-state DSSC with cyanidin as natural dye and $\mathrm{CuI}$ as inorganic hole transporter was first demonstrated 
T.-T. Bui and F. Goubard: Recent advances in small molecular, non-polymeric organic hole transporting material...

by Tennakone et al. [13] in 1995. In direct sunlight (ca. $800 \mathrm{Wm}^{-2}$ ) the cell generated a $J_{\mathrm{SC}}$ of $2.5 \mathrm{~mA} \mathrm{~cm}^{-2}$, a $V_{O C}$ of $375 \mathrm{mV}$ with the maximum energy conversion efficiency equal to $0.8 \%$. Since, the conversion efficiencies of cells employed inorganic $p$-type semiconductor electrolyte based solar cells have significantly increased. Recently, Chung et al. [14] have reported new efficient solution processable solid state DSSCs with $p$-type inorganic semiconductor $\mathrm{CsSnI}_{3}$ as hole conductor with a high hole mobility $\left(\mu_{h}=585 \mathrm{~cm}^{2} \mathrm{~V}^{-1} \mathrm{~s}^{-1}\right.$ at room temperature). With a bandgap of $1.3 \mathrm{eV}, \mathrm{CsSnI}_{3}$ enhances light absorption in visible domain to outperform the typical dye-sensitized solar cells. The cell sensitized with N719 using pristine $\mathrm{CsSnI}_{3}$ gave interesting photocurrent densityvoltage characteristics: $V_{O C}=0.638 \mathrm{~V}, F F=66.1 \%$, $J_{S C}=8.82 \mathrm{~mA} \mathrm{~cm}^{-2}, \eta=3.72 \%$. Moreover, the authors showed that doping of $\mathrm{CsSnI}_{3}$ with fluor and $\mathrm{SnF}_{2}$ dramatically improves these characteristics. At an optimum molar concentration of $5 \% \mathrm{~F}$ and $5 \% \mathrm{SnF}_{2}$, the cell exhibits the highest efficiency: $\eta=10.2 \%(\eta=8.51 \%$ with a mask $)$ under the standard AM 1.5 irradiation $\left(100 \mathrm{~mW} \mathrm{~cm}^{-2}\right)$.

The potential of ionic liquids as solvents for electrolytes for DSSCs has been also investigated during the last decade. The non-volatility, good solvent properties and high electrochemical stability of ionic liquids make them attractive solvents in contrast to volatile organic counterparts. However, the problem of leakage of the liquid electrolyte during the long-term operation is always persistent $[11,15]$. Then, polymeric ionic liquids, combining both features of ionic liquids and organic polymeric materials, have been used as a promising approach leading to high efficient devices. Recently, it was reported $\mathrm{I}_{2}$-free solid state DSSCs based on a solid state polymerized ionic liquids, i.e., poly(1-alkyl-3-(acryloyloxy)hexylimidazolium iodide) and poly((1-(4-ethenylphenyl)methyl)-3-butylimidazodium iodide) that can sufficiently penetrate the $\mathrm{TiO}_{2}$ nanopores. These devices exhibited cell efficiencies of 5.29 and $5.93 \%$, respectively, with an excellent longterm stability of the devices [16, 17]. Intrinsically, conducting polymers are well known as good hole transporting material, carrying current densities of several $\mathrm{mA} \mathrm{cm}{ }^{-2}$. Thus, these materials are potential candidates to use as HTM in solid state DSSCs. Nevertheless, polymers cast from solutions must penetrate into the pores of the nanoparticles and should form a good contact with the adsorbed sensitizer. Semiconducting polymer as poly(3,4-ethylenedioxythiophene) (PEDOT) [18, 19] and poly(3-hexylthiophene) (P3HT) [20] are mainly used in solid state DSSC as solid hole conductor [21]. However, the conversion efficiencies reported with conducting polymers as HTM are lower in comparison to the cells using a liquid electrolyte or small organic hole conductor molecules, mainly due to the incomplete filling of the $\mathrm{TiO}_{2}$ nanopores by the HTM [22], which leads to poor electronic contact between the dye molecules and the hole conductor. To overcome this drawback, in situ polymerized HTMs have been developed. The polymerization of monomers has taken place directly inside the $\mathrm{TiO}_{2}$ networks leading to high efficient solid state DSSCs with $\eta$ ranges from $\sim 4-7 \%$ [18, 19, 23-26]. A breakthrough was recently reported in solid-state hybrid solar cells by using organolead iodide perovskite $\left(\mathrm{CH}_{3} \mathrm{NH}_{3} \mathrm{PbI}_{3}\right)$ nanoparticles [27] as a light absorber and spiro-MeOTAD as HTM, which shows an impressive PCE of $9.7 \%$ with superior stability over 500 h. Etgar et al. [28] have described the photovoltaic device comprised of a mesoscopic $\mathrm{CH}_{3} \mathrm{NH}_{3} \mathrm{PbI}_{3} / \mathrm{TiO}_{2}$ heterojunction with $\mathrm{CH}_{3} \mathrm{NH}_{3} \mathrm{PbI}_{3}$ nanoparticles as both a light harvester and a HTM, which shows a high efficiency of $5.5 \%$ under 1 Sun illumination. Moreover, when the $n$-type semiconductor $\mathrm{TiO}_{2}$ was recently replaced by an insulating $\mathrm{Al}_{2} \mathrm{O}_{3}$ mesoporous scaffold, the device displayed a high $\mathrm{PCE}$ of $10.9 \%$, where a $\mathrm{CH}_{3} \mathrm{NH}_{3} \mathrm{PbI}_{2} \mathrm{Cl}$ thin absorber layer functions as both a light absorber and a charge transport materials [29].

In this short review, we limited our study on solid small molecular, non-polymeric organic hole conducting materials for solid state DSSCs.

\section{Molecular glasses based solid state DSSCs}

Historically, the first study concerning the use of molecular glasses as hole conductors in solid state DSSC was realized by Hagen et al. [30] in 1997. The solid state cells were prepared by evaporation of the $(N, N-9$ diphenyl- $N, N$-9-bis(3-methylphenyl)4,49-diamine (TPD) transport layer (Fig. 3) on a ruthenium complex sensitized nanoporous $\mathrm{TiO}_{2}$ (N3, Fig. 4). External quantum efficiencies of up to $0.2 \%$ was achieved with a low open circuit voltage equal to $300 \mathrm{mV}$ (Tab. 1). Poor titania pore filling has been reported as a major performance limiting factor in this study: the vacuum evaporation process involved a low interface between the dye and TPD yielding a low charge transfer between sensitized $\mathrm{TiO}_{2}$ and TPD.

Senadeera et al. [31] elaborated solid-state dyesensitized photocell based on pentacene (Fig. 3) as a hole collector, with N3 as sensitizer (Fig. 4). Pentacene was thermally evaporated in vacuum on top of the dye-coated $\mathrm{TiO}_{2}$ film to form films ca. $50 \mathrm{~nm}$ thick. Conductivity measurements on these iodine doped pentacene films revealed that conductivity is in the order of $1.25 \times 10^{-2} \mathrm{~S} \mathrm{~cm}^{-1}$, which was lower than that of pentacene films doped either with iodine or bromine reported in the literature (electrical conductivity of up to $100 \mathrm{~S} \mathrm{~cm}^{-1}$ ) [32,33]. Different film thickness, doping concentration and doping method might be reasons for this low value. Using an outer surface graphite-painted gold-plated FTO glass as counter electrode, the cell gave photovoltaic characterizations under illumination: $J_{S C}=3.6 \mathrm{~mA} \mathrm{~cm}{ }^{-2}, V_{O C}=415 \mathrm{mV}$, $F F=49 \%$ and $\eta=0.8 \%$. The low value of the efficiency can be explained by a partial absorption in visible light of the pentacene involving an overlap in absorption with the dye and cut off a significant amount of light reflected by the back contacts. Additionally, a low pore filling and a poor injection of the holes to the pentacene might decrease the photovoltaic efficiency.

In 1998, Salbeck et al. [34] and Bach et al. [35] reported the first dye-sensitized heterojunction of $\mathrm{TiO}_{2}$ 


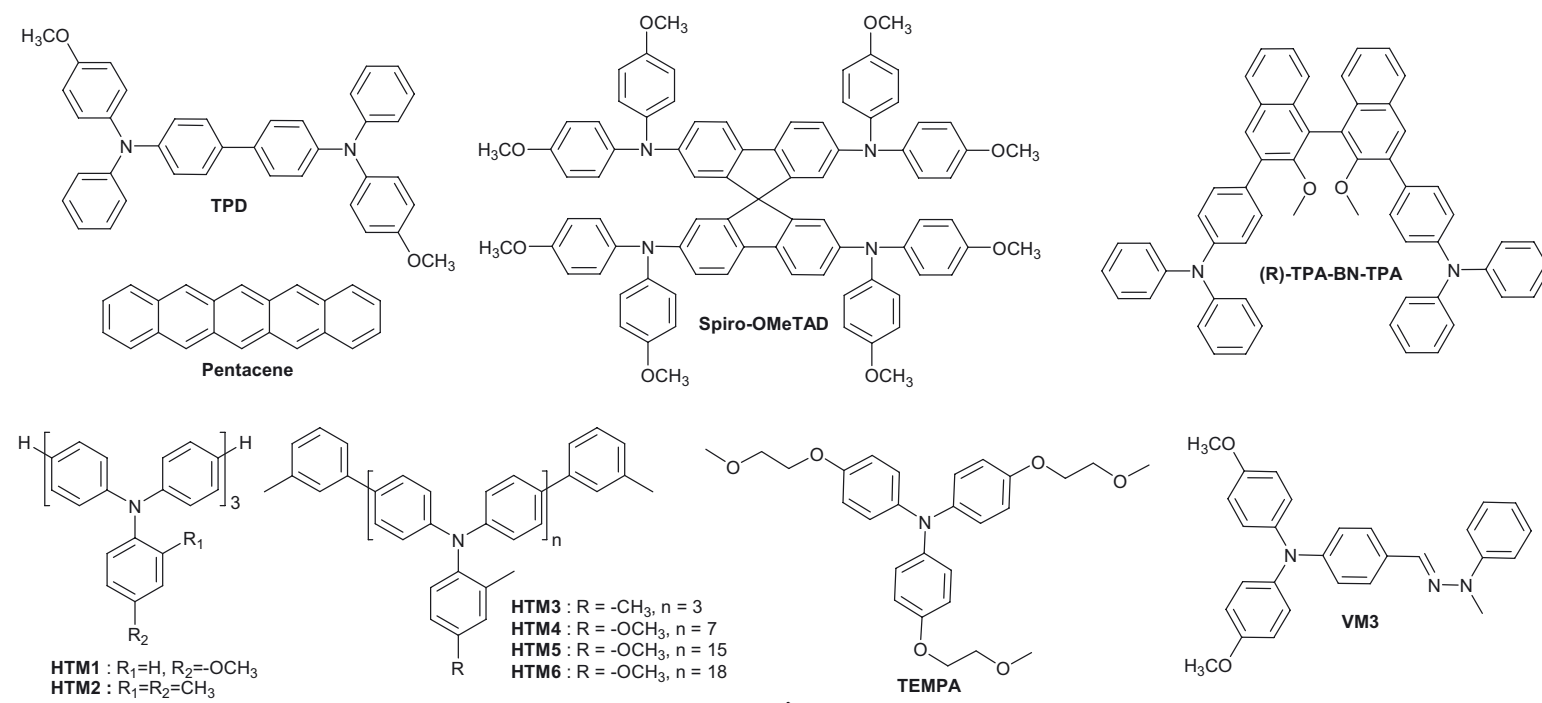<smiles>CN(/N=C\C1=CC=c2c3ccc(-c4ccc5c(c4)c4cc(/C=N\N(C)c6ccccc6)ccc4n5C)cc3c(n2C)=C1)c1ccccc1</smiles><smiles>[R6]c1ccc2ccccc2c1N(c1ccccc1)c1cc(N(c2ccccc2)c2c([2H])ccc3ccccc23)cc(N(c2ccccc2)c2c(F)ccc3ccccc23)c1</smiles><smiles>COc1ccc(N(c2ccc(OC)cc2)c2ccc3c(c2)C([13CH2])([14CH2])c2cc(N(c4ccc(OC)cc4)c4ccc(OC)cc4)ccc2-3)cc1</smiles><smiles>COc1ccc(N(c2ccc(OC)cc2)c2ccc3c4ccc(N(c5ccc(OC)cc5)c5ccc(OC)cc5)cc4n(C)c3c2)cc1</smiles><smiles>COc1ccccc1N(c1ccc2c(c1)c1ccccc1n2-c1ccccc1)c1ccccc1OC</smiles><smiles>COc1ccc(N(c2ccc(OC)cc2)c2ccc3c(c2)c2ccccc2n3-c2ccccc2)cc1</smiles><smiles>COc1ccccc1N(c1ccc2c(c1)c1c3ccccc3n(-c3ccccc3OC)c1n2-c1ccccc1)c1ccccc1N(c1ccccc1OC)c1ccccc1OC</smiles><smiles>[R]c1ccc(-c2ccc(N(c3ccc(-c4ccc([R])s4)cc3)c3ccc(-c4ccc(P)s4)cc3)cc2)s1</smiles>

Fig. 3. Chemical structures of organic hole transporters discussed in this article.

with the amorphous organic hole-transport material $2,2^{\prime}, 7,7^{\prime}$-tetrakis ( $N, N$-di- $p$-methoxyphenyl-amine) $9,9^{\prime}$ spirobifluorene (Spiro-OMeTAD) (Fig. 3), with an overall conversion efficiency of $0.74 \%$. Spiro-OMeTAD contains a spiro-centre (a tetrahedral carbon linking two aromatic moieties) which is introduced in order to improve the glass-forming properties and prevent crystallization of the organic material [36]. Its glass transition temperature of $T_{g}=120{ }^{\circ} \mathrm{C}$ is higher that of the widely used hole conductor TPD. Moreover, the methoxy groups are introduced in order to (i) match the oxidation potential of the hole-transport medium to that of the dye, (ii) move the absorption towards the UV domain thanks to their effect donor and (iii) make pore filling easier with a more hydrophilic molecule.

Usually, the photovoltaic efficiencies in solid state DSSC are dependent on the choice of the dye-HTM couple: a low interface or a screen effect in absorption between both molecules decreases considerably the overall conversion efficiency. In the case of the spiro-OMeTAD, the 
T.-T. Bui and F. Goubard: Recent advances in small molecular, non-polymeric organic hole transporting material...

Table 1. Photovoltaic properties of hole transporters discussed in this article.

\begin{tabular}{|c|c|c|c|c|c|c|c|c|}
\hline Compound & $\begin{array}{c}\mu_{h} \\
\left(\mathrm{~cm}^{2} \mathrm{~V}^{-1} \mathrm{~s}^{-1}\right)\end{array}$ & $\begin{array}{c}E_{\text {HOMO }} \\
(\mathrm{eV})\end{array}$ & $\begin{array}{c}\text { Sensitization } \\
\text { dye }\end{array}$ & $\begin{array}{c}J_{S C} \\
\left(\mathrm{~mA} / \mathrm{cm}^{2}\right) \\
\end{array}$ & $\begin{array}{c}V_{O C} \\
(\mathrm{mV})\end{array}$ & $\begin{array}{l}F F \\
(\%)\end{array}$ & $\begin{array}{c}\eta \\
(\%) \\
\end{array}$ & Ref. \\
\hline TPD & $10^{-3}$ & -5.06 & N3 $(\mathrm{Ru})$ & $\mathrm{n} / \mathrm{a}$ & 300 & $\mathrm{n} / \mathrm{a}$ & 0.2 & {$[30]$} \\
\hline Spiro-OMeTAD & $2 \times 10^{-4}$ & -4.77 & Y123 (OD) & 9.5 & 986 & 76 & 7.2 & {$[37]$} \\
\hline Pentacene & $\mathrm{n} / \mathrm{a}$ & $\mathrm{n} / \mathrm{a}$ & N3 $(\mathrm{Ru})$ & 3.6 & 415 & 49 & 0.8 & [31] \\
\hline HTM1 & $4.68 \times 10^{-4}$ & -4.97 & N719 $(\mathrm{Ru})$ & 3.8 & 789 & 67.1 & 2.01 & {$[48]$} \\
\hline HTM2 & $8.07 \times 10^{-4}$ & -5.0 & N719 $(\mathrm{Ru})$ & 1.69 & 750 & 34.9 & 0.44 & [48] \\
\hline НTM3 & $1.76 \times 10^{-3}$ & -4.99 & N719 (Ru) & 1.96 & 778 & 59.2 & 0.9 & [48] \\
\hline HTM4 & $2.06 \times 10^{-4}$ & -4.96 & N719 $(\mathrm{Ru})$ & 0.87 & 779 & 51.8 & 0.35 & {$[48]$} \\
\hline HTM5 & $8.23 \times 10^{-4}$ & -4.98 & N719 $(\mathrm{Ru})$ & 2.29 & 815 & 56.6 & 1.05 & [48] \\
\hline HTM6 & $1.04 \times 10^{-3}$ & -4.96 & N719 (Ru) & 2.51 & 797 & 49.5 & 0.99 & {$[48]$} \\
\hline (R)-TPA-BN-TPA & $\mathrm{n} / \mathrm{a}$ & $\mathrm{n} / \mathrm{a}$ & N719 $(\mathrm{Ru})$ & 1.07 & 887 & 58 & 0.55 & [49] \\
\hline HY-CARB & $6.4 \times 10^{-5}$ & -5.06 & N719 $(\mathrm{Ru})$ & 0.42 & 500 & 35 & 0.07 & [50] \\
\hline TMEPA & $\mathrm{n} / \mathrm{a}$ & -5.34 & $\mathrm{~K} 51(\mathrm{Ru})$ & 4.60 & 770 & 70 & 2.4 & {$[51]$} \\
\hline VM3 & $\mathrm{n} / \mathrm{a}$ & -5.25 & N719 $(\mathrm{Ru})$ & 0.332 & 521 & 43 & 0.075 & {$[52]$} \\
\hline $\mathrm{D}$ & $\mathrm{n} / \mathrm{a}$ & -5.70 & Red sandal (OD) & 0.9 & 250 & $\mathrm{n} / \mathrm{a}$ & 0.39 & {$[53]$} \\
\hline AS37 & $5 \times 10^{-5}$ & -4.98 & Z907 (Ru) & 5.5 & 730 & 62 & 2.48 & {$[54]$} \\
\hline AS44 & $1 \times 10^{-5}$ & -4.99 & $\mathrm{Z} 907(\mathrm{Ru})$ & 6.0 & 730 & 67 & 2.94 & {$[54]$} \\
\hline $4 \mathrm{~d}$ & $\mathrm{n} / \mathrm{a}$ & -4.82 & D102 (OD) & 2.63 & 630 & 32 & 0.54 & {$[55]$} \\
\hline $4 \mathrm{~b}$ & $7.4 \times 10^{-5}$ & -4.92 & D102 (OD) & 0.75 & 573 & 28 & 0.12 & {$[55]$} \\
\hline $5 b$ & $1 \times 10^{-3}$ & -4.86 & D102 (OD) & 1.72 & 531 & 35 & 0.32 & {$[55]$} \\
\hline TVT & $\mathrm{n} / \mathrm{a}$ & $\mathrm{n} / \mathrm{a}$ & $\mathrm{SQ}(\mathrm{OD})$ & 0.64 & 480 & 64 & 0.19 & {$[56]$} \\
\hline VM5C9 & $\mathrm{n} / \mathrm{a}$ & -5.21 & D102 (OD) & 1.83 & 680 & 38 & 0.47 & {$[57]$} \\
\hline
\end{tabular}

n/a: not available; (OD): organic dye; $(\mathrm{Ru})$ : ruthenium complex.

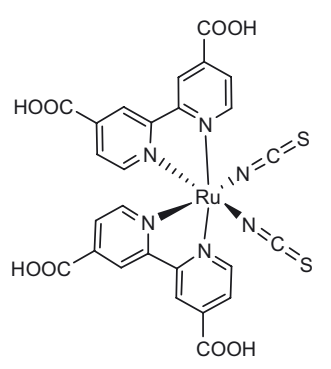

N3

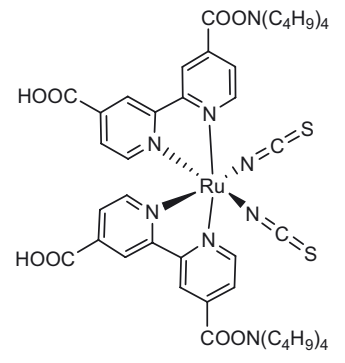

N719

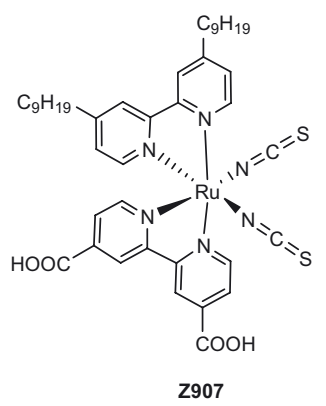

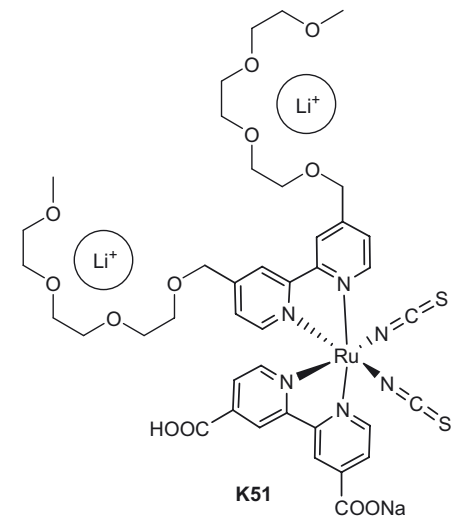

Organic dyes
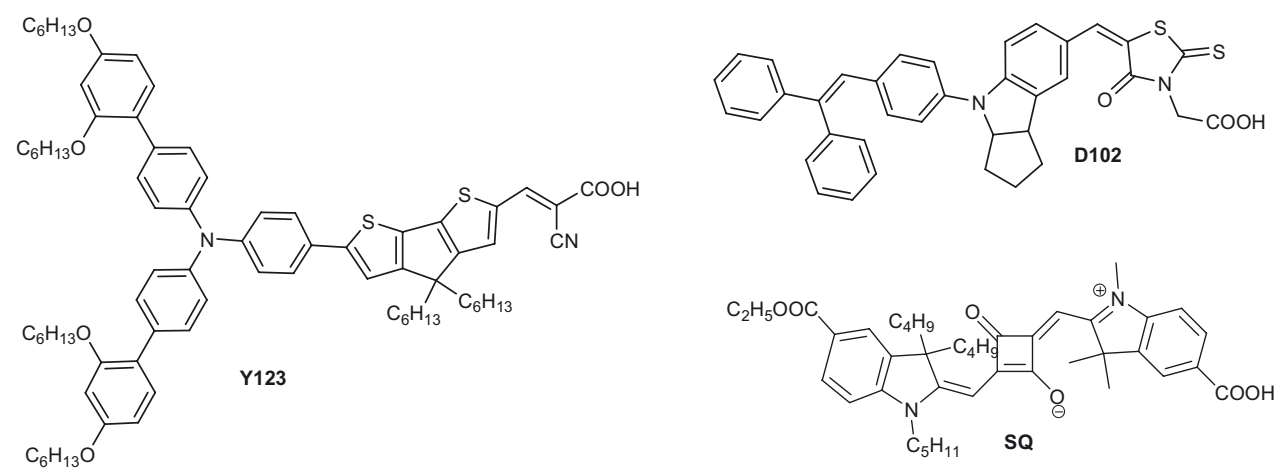

Fig. 4. Chemical structures of photosensitizers associated with hole transporters discussed in this article. 
evolution of both the nanostructuration of $\mathrm{TiO}_{2}$ and the synthesis of new dyes (mainly organic dyes) allowed a considerable increase of photovoltaic efficiencies with a record in 2011 in $7.2 \%$ thanks to the organic dye Y123 (Fig. 4) by Burschka et al. [37]. The inorganic dye based solar devices have attracted considerable attention in recent years as they offer high and interesting overall conversion efficiency: recently, Kim et al. [27] reported on solid-state mesoscopic heterojunction solar cells employing nanoparticles of methyl ammonium lead iodide $\left(\mathrm{CH}_{3} \mathrm{NH}_{3}\right) \mathrm{PbI}_{3}$ as light harvesters yielding a power conversion efficiency of $9.7 \%$. Moreover, Lee et al. [29] replaced $\mathrm{TiO}_{2}$ anode by mesoporous alumina as an inert scaffold in sensitized solar cells: with intense visible to near-infrared absorptivity by the highly crystalline perovskite as absorber, the power conversion efficiency of $10.9 \%$ in a single-junction device under simulated full sunlight is observed. Electron transfer is then carried out on the oxide surface and through the perovskite.

Moreover, the hole conduction of spiro-OMeTAD increased by adding lithium bistrifluoromethylsulfonyl imide, $\left(\mathrm{Li}\left[\left(\mathrm{CF}_{3} \mathrm{SO}_{2}\right)_{2} \mathrm{~N}\right]\right)$ as an electrolytic salt and tert-butylpyridine (tBP) as solvent. This salt addition improves the performances in terms of photocurrent, open circuit voltage [38] and hole mobility [39,40]. Upon the addition of lithium salts to the spiroOMeTAD hole-transporter matrix, Snaith et al. [39] observe a 100-fold increase in conductivity through spiro-MeOTAD within a dye-sensitized $\mathrm{TiO}_{2}$ mesoporous network. By making "hole-only" diodes of pure spiro-MeOTAD and those doped with lithium salts, the authors calculate that the hole mobility increases from $1.6 \times 10^{-4}$ to $1.6 \times 10^{-3} \mathrm{~cm}^{2} / \mathrm{V}$ s. Using a molecular hole conductor (4,4",4"',4"'"-ter- N,N-diphenyl[4(methoxymethyl)phenyl]-amine), Snaith and Grätzel [41] have also shown that under illumination, the hole density increases, resulting in striking enhancements in film conductivity, up to $10^{6}$ times, and charge carrier mobility, up to $10^{3}$ times (hole mobility increases from $2.0 \times 10^{6}$ to $1.2 \times 10^{-3} \mathrm{~cm}^{2} / \mathrm{V}$ s when increasing the incident illu-

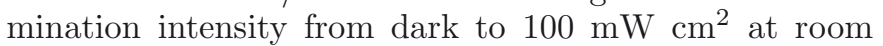
temperature. Moreover, 4-trimethylsilylpyridine as the replacement for tBP involved a $10 \%$ increase of overall conversion efficiency [42].

The rate of pore filling by the molecular glass is also an important parameter for optimal overall conversion efficiency. Infiltration of molecular glasses into mesoporous $\mathrm{TiO}_{2}$ film is usually accomplished by depositing molecular glass solution on the film and soaking the film for 1 minute, followed by spin coating to remove excess solution. By this way and with spiro-OMeTAD the filling fraction is as high as $60-70 \%$ for films with thickness $<3 \mu \mathrm{m}$; however, as the film thickness increases, the filling fraction goes down, which may be the cause of poor efficiency of these devices $[43,44]$. Moreover, the coating method could influence the pore filling: Doctor blade coating is more adapted for the higher thickness [45]. Melhem et al. [46] demonstrated also different filling fraction depending on crystalline morphology of $\mathrm{TiO}_{2}$.
The other structures of studied molecular glasses are mainly arylamine derivatives [47]: the hydrogen atoms of the phenyls near the nitrogen atom create between them a steric hindrance inducing the three-dimensional structure and consequently an amorphous state over the ambient temperature like spiro-OMeTAD. Kroeze et al. [48] studied oligomers HTM with core triphenylamine of variable molecular masses (HTM1 to HTM6, Fig. 3), and showed in particular, higher efficiencies when the number of entity decrease. Furthermore, the valuable difference of mobility values, contrary to the filling, is not correlable in the performances of cells. Also let us note that these values of mobility are the same order as those of spiro-OMeTAD but the performances are much lower. It can be the consequence of a difficult penetration of these oligomers in the porous anode.

As described above, the active layer of solid-state DSSC is comprised of a nanostructured $\mathrm{TiO}_{2}$ film coated with a monolayer of photosensitizer and infiltrated with an organic electron-donating/hole-transporting semiconductor. The most successful approach is to spin-coat a highly concentrated solution of hole transporter on top of the nanoporous film, allowing the favorable interaction between the hole transporter and the dye-coated surface to act as a driving force to aid material infiltration during solvent evaporation. However, this later step is far from perfect and it is still difficult to obtain material infiltration through more than a few micrometers thickness. Snaith et al. [51] have, therefore, suggested that a liquid organic semiconductor may offer the ideal solution, enabling infiltration without the need for subsequent solvent evaporation. They have synthesized tris-[4-(2-methoxy-ethoxy)-phenyl]-amine (TMEPA, Fig. 3) which absorbs only in the UV region. Due to the methoxy-ethoxy side-chain's characteristics, TMEPA is in a liquid state at room temperature $\left(T_{g}=-14^{\circ} \mathrm{C}\right.$, $\left.T_{m}=-7{ }^{\circ} \mathrm{C}\right)$. DSSC fabricated from $\mathrm{NOBF}_{4}$ chemically doped TMEPA and K51-sensibilized porous anode delivered a power conversion efficiency of $2.4 \%$ with a quantum efficiency of over $50 \%$.

In 2007, Zhao et al. [49] reported a newly chiral small organic hole conductor, (R)-2,20-dimethoxyl-3, 3'-di(phenyl-4-yl-diphenyl-amine)-[1,10]-binaphthyl ((R)TPABN- TPA, Fig. 3). This molecule features two triphenylamine and two methoxynaphthalene moieties. Introduced into dye-sensitized photoelectrical cell as solidstate electrolyte, the device converted light to electricity with an efficiency of $0.07 \%$ without any additives in electrolyte. The solid-state devices showed an attractive conversion efficiency of up to $0.55 \%$ with the assistance of some functional small-molecules in the electrolyte. This amelioration is attributed to the positive effects of functional additives (tBP, $\left.\mathrm{Li}\left[\left(\mathrm{CF}_{3} \mathrm{SO}_{2}\right)_{2} \mathrm{~N}\right], \mathrm{N}(\mathrm{PhBr})_{3} \mathrm{SbCl}_{6}\right)$ such as inhibiting interface charge recombination, improving hole-transporting properties and penetration of solidstate electrolyte.

In 2008, our group reported a new class of hole transporting molecular glasses based on hydrazone derivatives (HY-CARB, Fig. 3) [50,58]. Thermal and 
T.-T. Bui and F. Goubard: Recent advances in small molecular, non-polymeric organic hole transporting material...

optoelectrochemical investigations revealed interesting properties suitable for solid-state dye-sensitized solar cell application. With an optical gap of $3.1 \mathrm{eV}$, which is large enough to avoid screening effect in absorption with dye, and a HOMO energy level close to $-5.06 \mathrm{eV}, \mathrm{HY}-$ CARB is well adapted for the regeneration of the photooxidized ruthenium dye $\left(E_{\mathrm{HOMO}}=-5.45 \mathrm{eV}\right)$. Indeed, differential scanning calorimetric characterizations confirm the metastable amorphous properties of HY-CARB with glass transition temperature at $76{ }^{\circ} \mathrm{C}$. Without any additives, the solid-state DSSC based on N719-sensitized $\mathrm{TiO}_{2}$ anode give the following photovoltaic characteristics: $V_{O C}=230 \mathrm{mV}, F F=29 \%$ and $J_{S C}=1 \mu \mathrm{A} / \mathrm{cm}^{2}$. Upon adding $\mathrm{NOBF}_{4}$ and $\mathrm{Li}\left[\left(\mathrm{CF}_{3} \mathrm{SO}_{2}\right)_{2} \mathrm{~N}\right.$ into electrolyte, photovoltaic output was significantly improved $\left(J_{S C}=\right.$ $0.42 \mathrm{~mA} \mathrm{~cm}^{-2}, V_{O C}=500 \mathrm{mV}$ et $F F=35 \%$ ). However, it is still far from satisfactory. The low hole mobility $\left(6.4 \times 10^{-5} \mathrm{~cm}^{2} \mathrm{~V}^{-1} \mathrm{~s}^{-1}\right)$, as well as the poor infiltration into the nanoporous oxide layer because of its hydrophobic structure seem to be the cause of this unsatisfactory performance.

Juozapavicius et al. [52] have reported a molecular glass featuring hydrazone and triphenylamine moieties (VM3, Fig. 3). Designed for the development of solventfree, melt-infiltration process, VM3 has relatively low melting point $\left(134^{\circ} \mathrm{C}\right)$. Based on transient absorption spectroscopy measurement, the authors have proved a good efficiency of dye regeneration suggesting a good hole transporter infiltration. However, low photocurrent lead to low light to electricity conversion yield $(\eta=0.075 \%$ with electrolyte doped by iodine vapor).

Mathew and Haridas [53] have recently reported a starburst naphthylamine-based molecular glass hole conductor $\left(T_{g}=80{ }^{\circ} \mathrm{C}\right)$, named $N, N, N^{\prime}$-tris- $(2$ ethoxy-naphthalene-1-yl) $N, N, N^{\prime}$-triphenylbenzene1,3,5triamine (D, Fig. 3). Using this compound as solid electrolyte, natural-organic-dye-sensitized solar cell was fabricated and the performance was analyzed. Despite unsatisfactory photovoltaic output performance $(0.39 \%)$, the authors highlight the economical aspect of these cells: the total cost is down to nearly $30-40 \%$ of a similar type of fabricated cell.

Recently, Leijtens et al. [54] have reported two new hole transporters, both containing double di(4methoxyphenyl)amino moieties (AS37 et AS44, Fig. 3). Conceptually, the new HTMs were designed to have similar functional groups and energy levels close to that of spiro-OMeTAD but differ in molecular size, solubility, glass transition temperature, and melting point. AS37 can be considered as a half of Spiro-OMeTAD, where the central spiro-link was replaced by two hexyl chains. In the other hand, replacement of the spiro-bridge by carbazole core, which is more electron donating than fluorene core, lead to AS44 In addition to possessing high solubility, their optoelectrochemical and electrical properties well suited for solid-state DSSC. These molecules have relatively low glass transition temperature and melting point than that of Spiro-OMeTAD $\left(\mathrm{AS} 37: T_{g}=43{ }^{\circ} \mathrm{C}\right.$, $T_{f}=106{ }^{\circ} \mathrm{C}$, AS44: $\left.T_{g}=59{ }^{\circ} \mathrm{C}, T_{f}=132{ }^{\circ} \mathrm{C}\right)$. Using standard device fabrication methods with Z907-sensitized $\mathrm{TiO}_{2}$ nanoporous anode, interesting power conversion efficiencies of $2.94 \%$ (AS44) and $2.48 \%$ (AS37) in 2- $\mu$ m-thick cells were achieved. In $6-\mu \mathrm{m}$-thick cells, the device performance is shown to be higher than that obtained using spiro-OMeTAD in the same condition despite their lower hole mobility, making these new HTMs promising for preparing high-efficiency solid-state DSSCs. The authors suggested that the high solubility of the new materials result in significantly improved pore filling in thick devices, thus photovoltaic performance.

Tomkeviciene et al. [55] have recently synthesized a series of molecular glasses based on 9-phenylcarbazole (4b, 4d, and 5b, Fig. 3). All of these compounds contain bis(methoxyphenyl)amino functional groups with methoxy groups in the different position of diphenylamino. These bis(methoxyphenyl)amino moieties modulate the optoelectronic and thermal properties of targeted molecules. In addition to possessing high solubility, high thermal stability $\left(T_{d}=344-475{ }^{\circ} \mathrm{C}\right)$, stable amorphous state $\left(T_{g}=65-89^{\circ} \mathrm{C}\right)$, their optical, photoelectrical and electrochemical properties are well suited for photovoltaic application. The derivatives were tested as hole transport materials in solid-state D102-sensitized solar cells and showed overall conversion efficiency of up to $0.54 \%$.

Recently, Unger et al. [56] has reported a star-shapped hole transporting molecular glass absorbing in the visible spectral domain, named tris(thienyl-vinyl-thienyl)triphenylamine (TVT, Fig. 3). Associated with a near infrared harvesting squaraine dye (SQ, Fig. 4) in solid-state DSSC, it has been demonstrated that TVT contributes to the photocurrent. Energy transfer from TVT to SQ was investigated by photoluminescence emission and excitation measurements and the excitation energy transfer efficiency from TVT to SQ was determined to be $26 \%$. The low power conversion efficiency $(0.19 \%)$ may be due to the slow regeneration of SQ by TVT and narrow absorption band of SQ.

Our group has recently reported a starbust triphenylamine-based molecular glass (VM5C9, Fig. 3) absorbing strongly in the visible spectral domain $\left(\lambda_{\max }=428 \mathrm{~nm} / \varepsilon=131000 \mathrm{~L} \mathrm{~mol}^{-1} \mathrm{~cm}^{-1}\right)[57,59]$, which was successfully employed in solid-state DSSCs. The device made from a spin-coated thin film of VM5C9 onto a $\mathrm{TiO}_{2}$ nanoporous anode (no dye-coated) delivered an overall energy conversion yield of $0.3 \%$ after cathode $\mathrm{Au})$ evaporation. It is noteworthy to note that, in this device, VM5C9 played a double role as photosensitizer and also as electron-donating/hole transporter. In the other hand, VM5C9 was not chemically absorbed onto $\mathrm{TiO}_{2}$ surface by covalent bonds. By using a D102sensitized anode, the performance of the obtained device increased to $0.47 \%$. Our first investigations suggest that poor pore filling and strong screen effect in absorption between VM5C9 and D102 caused this unsatisfactory performance. We are actively working on the device optimization and concerning results will be published elsewhere shortly. 
From the analysis of photovoltaic properties of different hole transporters cited in the article, it appears that rational design of new hole transporter need some requirements. However some criteria are more relevant than other ones.

- High hole mobility is desirable but not vital. The hole drift speed should be at least in the same magnitude to that of the electrons in inorganic semiconductor porous network. Best results in $\mathrm{PCE}$ with $\mathrm{TiO}_{2} /$ dye/ spiro-OMeTAD were obtained with charge mobilities of $10^{-4}-10^{-3} \mathrm{~cm}^{2} / \mathrm{V}$ s.

- The energy level of the HOMO of hole conductor must be slightly higher than that of the photosensitizer. A difference of $0.3-0.4 \mathrm{eV}$ is requested in order to ensure good hole injection from excited photosensitizer toward hole transporter.

- The screen effect in absorption between the electrolytic molecular glass and the photosensitizer should be avoided. Competing absorption between these two components conducts to a bad impact on the photovoltaic efficiency of devices. Ideally, the hole transporter should only absorb in the UV spectral domain to ensure a good compatibility with larger range of photosensitizer.

- Good penetration of hole conductor into the mesoporous titanium dioxide networks is vital. Contrary to liquid-based electrolyte DSSC where liquid electrolyte can penetrate easily and deeply into $\mathrm{TiO}_{2}$ anode, the pore filling of solid organic hole transporters stands only around $60-70 \%$. The insufficient pore-filling of HTM causes lower photocurrent and poorer performance under full sunlight and faster recombination as well. The pore filling should be taken into account in designing new molecules as dye or HTM for sDSSC application. For example: dyes having similar functional group to methoxyphenyl amine group on spiroOMeTAD could have a favorable contact between dye molecules and HTM, and this good contact can lead to better pore-filling. Additionally, the long alkyl chains help to promote pore-filling of the HTM due to their strong hydrophobicity. Moreover, the presence of a long alkyl chain retarded charge recombination and increased electron lifetime [60].

- Finally, in terms of morphological stability, glass transition should occur at high temperature, ideally higher than $80^{\circ} \mathrm{C}$. The cell temperature can increase under continuous full sunlight illumination, which leads to morphological changes in the layer of hole conductor if its $T_{g}$ is too low.

\section{Conclusion and outlook}

Since one decade, the performance of solid-state dyesensitized solar cells has been made remarkable progress. In this article, we review current progress in the use of organic molecular glasses as hole transporting materials in these devices. Contrary to liquid-based electrolyte DSSCs, interfacial issues of mesoporous $\mathrm{TiO}_{2} /$ colorant/ hole transporter are more critical and greatly influent the photovoltaic performance of devices. New hole transporter's conception and chemical molecular engineering focus primarily on the delicate balance of HOMO-LUMO energy levels/no screen effect in absorption with photosensitizer/infiltration into the mesoporous metal oxide network. Many molecular glasses hole transporters have been reported in the literature. Structurally, these compounds are all tertiary arylamine derivatives. The introduction of methoxy hydrophilic units in the molecular structure seems to be primordial. These groups help to modulate the optoelectronic and thermal properties of the targeted molecule. On the other hand, the penetration of molecular glasses into porous networks is favored leading to more efficient devices. Currently, hole transporting materials based on arylamines are dominant and the most efficient is spiro-OMeTAD.

But still several critical issues should be resolved in solid DSSC: incomplete pore-filling of the spiro-OMeTAD, stability of the cell, and low light harvesting efficiency. As well as, new hole transporting materials should be developed in order to enhance a photovoltaic performance, the device efficiency can be improved by applying new light absorbing materials with high molar extinction coefficient or modifications of the mesoporous $\mathrm{TiO}_{2}$ layer.

\section{References}

1. D.M. Chapin, C.S. Fuller, G.L. Pearson, J. Appl. Phys. 25, 676 (1954)

2. J. Bisquert, Chem. Phys. Chem. 12, 1633 (2011)

3. A. Hagfeldt, G. Boschloo, L. Sun, L. Kloo, H. Pettersson, Chem. Rev. 110, 6595 (2010)

4. M. Grätzel, Inorg. Chem. 44, 6841 (2005)

5. B. O'Regan, M. Grätzel, Nature 353, 737 (1991)

6. M. Grätzel, Acc. Chem. Res. 42, 1788 (2009)

7. Y. Chiba, A. Islam, Y. Watanabe, R. Komiya, N. Koide, L. Han, Jpn J. Appl. Phys. 45, L638 (2006)

8. A. Yella, H.-W. Lee, H.N. Tsao, C. Yi, A.K. Chandiran, M.K. Nazeeruddin, E.W.-G. Diau, C.-Y. Yeh, S.M. Zakeeruddin, M. Grätzel, Science 334, 629 (2011)

9. M.A. Green, K. Emery, Y. Hishikawa, W. Warta, E.D. Dunlop, Prog. Photovolt.: Res. Appl. 20, 606 (2012)

10. J.B. Baxter, J. Vac. Sci. Technol. A 30, 020801 (2012)

11. S.M. Zakeeruddin, M. Grätzel, Adv. Funct. Mater. 19, 2187 (2009)

12. L.M. Peter, J. Phys. Chem. Lett. 2, 1861 (2011)

13. K. Tennakone, G.R.R.A. Kumara, A.R. Kumarasinghe, K.G.U. Wijayantha, P.M. Sirimanne, Semicond. Sci. Technol. 10, 1689 (1995)

14. I. Chung, B. Lee, J. He, R.P.H. Chang, M.G. Kanatzidis, Nature 485, 486 (2012)

15. M. Gorlov, L. Kloo, Dalton Trans. 20, 2655 (2008)

16. W.S. Chi, J.K. Koh, S.H. Ahn, J.-S. Shin, H. Ahn, D.Y. Ryu, J.H. Kim, Electrochem. Commun. 13, 1349 (2011)

17. G. Wang, L. Wang, S. Zhuo, S. Fang, Y. Lin, Chem. Commun. 47, 2700 (2011)

18. J.K. Koh, J. Kim, B. Kim, J.H. Kim, E. Kim, Adv. Mater. 23, 1641 (2011)

19. J. Kim, J.K. Koh, B. Kim, S.H. Ahn, H. Ahn, D.Y. Ryu, J.H. Kim, E. Kim, Adv. Funct. Mater. 21, 4633 (2011) 
T.-T. Bui and F. Goubard: Recent advances in small molecular, non-polymeric organic hole transporting material...

20. W. Zhang, R. Zhu, F. Li, Q. Wang, B. Liu, J. Phys. Chem. C 115, 7038 (2011)

21. W. Zhang, Y. Cheng, X. Yin, B. Liu, Macromol. Chem. Phys. 212, 15 (2011)

22. L. Yang, U.B. Cappel, E.L. Unger, M. Karlsson, K.M. Karlsson, E. Gabrielsson, L. Sun, G. Boschloo, A. Hagfeldt, E.M.J. Johansson, Phys. Chem. Chem. Phys. 14, 779 (2012)

23. X. Liu, Y. Cheng, L. Wang, L. Cai, B. Liu, Phys. Chem. Chem. Phys. 14, 7098 (2012)

24. I.Y. Song, S.-H. Park, J. Lim, Y.S. Kwon, T. Park, Chem. Commun. 47, 10395 (2011)

25. B. Kim, J.K. Koh, J. Kim, W.S. Chi, J.H. Kim, E. Kim, ChemSusChem. 5, 2173 (2012)

26. X. Liu, W. Zhang, S. Uchida, L. Cai, B. Liu, S. Ramakrishna, Adv. Mater. 22, E150 (2010)

27. H.-S. Kim, C.-R. Lee, J.-H. Im, K.-B. Lee, T. Moehl, A. Marchioro, S.-J. Moon, R. Humphry-Baker, J.-H. Yum, J.E. Moser, M. Grätzel, N.-G. Park, Sci. Rep. 2, 591 (2012)

28. L. Etgar, P. Gao, Z. Xue, Q. Peng, A.K. Chandiran, B. Liu, M.K. Nazeeruddin, M. Grätzel, J. Am. Chem. Soc. 134, 17396 (2012)

29. M.M. Lee, J. Teuscher, T. Miyasaka, T.N. Murakami, H.J. Snaith, Science 338, 643 (2012)

30. J. Hagen, W. Schaffrath, P. Otschik, R. Fink, A. Bacher, H.-W. Schmidt, D. Haarer, Synth. Met. 89, 215 (1997)

31. G.K.R. Senadeera, P.V.V. Jayaweera, V.P.S. Perera, K. Tennakone, Sol. Energy Mater. Sol. Cells 73, 103 (2002)

32. T. Minakata, I. Nagoya, M. Ozaki, J. Appl. Phys. 69, 7354 (1991)

33. T. Minakata, H. Imai, M. Ozaki, K. Saco, J. Appl. Phys. 72, 5220 (1992)

34. J. Salbeck, N. Yu, J. Bauer, F. Weissortel, H. Bestgen, Synth. Met. 91, 209 (1997)

35. U. Bach, D. Lupo, P. Comte, J.E. Moser, F. Weissortel, J. Salbeck, H. Spreitzer, M. Grätzel, Nature 395, 583 (1998)

36. R. Pudzich, T. Fuhrmann-Lieker, J. Salbeck, Adv. Polym. Sci. 199, 83 (2006)

37. J. Burschka, A. Dualeh, F. Kessler, E. Baranoff, N.-L. Cevey-Ha, C. Yi, M.K. Nazeeruddin, M. Grätzel, J. Am. Chem. Soc. 133, 18042 (2011)

38. J. Krüger, R. Plass, L. Cevey, M. Piccirelli, M. Grätzel, U. Bach, Appl. Phys. Lett. 79, 2085 (2001)

39. H.J. Snaith, M. Grätzel, Appl. Phys. Lett. 89, 262114 (2006)

40. G. Boschloo, L. Haggman, A. Hagfeldt, J. Phys. Chem. B 110, 13144 (2006)

41. H.J. Snaith, M. Grätzel, Phys. Rev. Lett. 98, 177402 (2007)
42. K. Kakiage, T. Tsukahara, T. Kyomen, M. Unno, M. Hanaya, Chem. Lett. 41, 895 (2012)

43. H.J. Snaith, R. Humphry-Baker, P. Chen, I. Cesar, S.M. Zakeeruddin, M. Grätzel, Nanotechnology 19, 424003 (2008)

44. I.-K. Ding, N. Tetreault, J. Brillet, B.E. Hardin, E.H. Smith, S.J. Rosenthal, F. Sauvage, M. Grätzel, M.D. McGehee, Adv. Funct. Mater. 19, 2431 (2009)

45. I.K. Ding, J. Melas-Kyriazi, N.-L. Cevey-Ha, K.G. Chittibabu, S.M. Zakeeruddin, M. Grätzel, M.D. McGehee, Org. Electron. 11, 1217 (2010)

46. H. Melhem, P. Simon, L. Beouch, F. Goubard, M. Boucharef, C. Di Bin, Y. Leconte, B. Ratier, N. HerlinBoime, J. Bouclé, Adv. Energy Mater. 1, 908 (2011)

47. C.-Y. Hsu, Y.-C. Chen, R.Y.-Y. Lin, K.-C. Ho, J.T. Lin, Phys. Chem. Chem. Phys. 14, 14099 (2012)

48. J.E. Kroeze, N. Hirata, L. Schmidt-Mende, C. Orizu, S.D. Ogier, K. Carr, M. Grätzel, J.R. Durrant, Adv. Funct. Mater. 16, 1832 (2006)

49. Y. Zhao, W. Chen, J. Zhai, X. Sheng, Q. He, T. Wei, F. Bai, L. Jiang, D. Zhu, Chem. Phys. Lett. 445, 259 (2007)

50. R. Aich, F. Tran-Van, F. Goubard, L. Beouch, A. Michaleviciute, J.V. Grazulevicius, B. Ratier, C. Chevrot, Thin Solid Films 516, 7260 (2008)

51. H.J. Snaith, S.M. Zakeeruddin, Q. Wang, P. Pechy, M. Grätzel, Nano Lett. 6, 2000 (2006)

52. M. Juozapavicius, B.C. O'Regan, A.Y. Anderson, J.V. Grazulevicius, V. Mimaite, Org. Electron. 13, 23 (2012)

53. S. Mathew, K.R. Haridas, Bull. Mater. Sci. 35, 123 (2012)

54. T. Leijtens, I.K. Ding, T. Giovenzana, J.T. Bloking, M.D. McGehee, A. Sellinger, ACS Nano 6, 1455 (2012)

55. A. Tomkeviciene, G. Puckyte, J.V. Grazulevicius, M. Degbia, F. Tran-Van, B. Schmaltz, V. Jankauskas, J. Bouclé, Synth. Met. 162, 1997 (2012)

56. E.L. Unger, A. Morandeira, M. Persson, B. Zietz, E. Ripaud, P. Leriche, J. Roncali, A. Hagfeldt, G. Boschloo, Phys. Chem. Chem. Phys. 13, 20172 (2011)

57. N. Metri, X. Sallenave, C. Plesse, L. Beouch, P.-H. Aubert, F. Goubard, C. Chevrot, G. Sini, J. Phys. Chem. C 116, 3765 (2012)

58. F. Goubard, R. Aîch, F. Tran-Van, A. Michaleviciute, F. Wünsch, M. Kunst, J. Grazulevicius, B. Ratier, C. Chevrot, Proc. Estonian Acad. Sci. Eng. 12, 96 (2006)

59. N. Metri, X. Sallenave, L. Beouch, C. Plesse, F. Goubard, C. Chevrot, Tetrahedron Lett. 51, 6673 (2010)

60. Z.-S. Wang, N. Koumura, Y. Cui, M. Takahashi, H. Sekiguchi, A. Mori, T. Kubo, A. Furube, K. Hara, Chem. Mater. 20, 3993 (2008)

Cite this article as: Thanh-Tuan Bui, Fabrice Goubard, Recent advances in small molecular, non-polymeric organic hole transporting materials for solid-state DSSC, EPJ Photovoltaics 4, 40402 (2013). 